\title{
n-Propanol extract of boiled and fermented koro benguk (Mucuna pruriens seed) shows a neuroprotective effect in paraquat dichloride-induced Parkinson's disease rat model
}

\author{
Yosua Kristian Adi ${ }^{1}$, Rini Widayanti² and Tri Wahyu Pangestiningsih ${ }^{3}$
}

1. Master Program of Veterinary Science, Faculty of Veterinary Medicine, Universitas Gadjah Mada, Yogyakarta, Indonesia; 2. Department of Biochemistry, Faculty of Veterinary Medicine, Universitas Gadjah Mada, Yogyakarta, Indonesia; 3. Department of Anatomy, Faculty of Veterinary Medicine, Universitas Gadjah Mada, Yogyakarta, Indonesia. Corresponding author: Tri Wahyu Pangestiningsih, e-mail: estifkh@ugm.ac.id

Co-authors: YKA: yosua.kristian.a@mail.ugm.ac.id, RW: rini_widayanti@ugm.ac.id

Received: 04-01-2018, Accepted: 26-07-2018, Published online: 12-09-2018

doi: 10.14202/vetworld.2018.1250-1254 How to cite this article: Adi YK, Widayanti R, Pangestiningsih TW (2018) n-Propanol extract of boiled and fermented koro benguk (Mucuna pruriens seed) shows a neuroprotective effect in paraquat dichloride-induced Parkinson's disease rat model, Veterinary World, 11(9): 1250-1254.

\begin{abstract}
Aim: n-Propanol extracts from fresh, boiled, and fermented seeds were studied to evaluate their neuroprotective effects in a Parkinson's disease (PD) rat model, based on the total number of dopaminergic (DA) neurons in the substantia nigra pars compacta (SNpc).

Materials and Methods: Rats were induced with paraquat dichloride at a dosage of $7 \mathrm{mg} / \mathrm{kg} \mathrm{BW}$ intraperitoneally twice a week and at the same time supplemented with extract at a dosage of $70 \mathrm{mg} / \mathrm{kg} \mathrm{BW}$ orally every day for 3 weeks. On the $24^{\text {th }}$ day, all rats were perfused and fixed with $4 \%$ paraformaldehyde. The left part of the SNpc was processed for immunohistochemical staining with tyrosine hydroxylase $(\mathrm{TH})$-antibody. The total number of DA neurons in SNpc was evaluated with a stereological method.
\end{abstract}

Results: TH-immunoreactive cells found in the SNpc were identified as DA neurons. The average total number of DA neurons in the SNpc increased significantly in the PD rat model that was given an n-propanol extract of boiled and fermented seeds compared with a control PD rat model. Surprisingly, there was no significant difference in the average total number of DA neurons in SNpc between the PD rat model that was given n-propanol extract of fresh seeds and the control PD rat model.

Conclusion: n-Propanol extract of boiled and fermented seeds could produce a higher neuroprotective effect against DA neuron than fresh seeds in a PD rat model.

Keywords: animal model, Mucuna pruriens, neuroprotective, paraquat dichloride, Parkinson's disease.

\section{Introduction}

At present, human life expectancy is increasing. Based on data from the World Health Organization, the number of people aged over 65 will have risen from 390 million in 1997 to 800 million in 2025 [1]. However, aging of the population is also followed by an increasing number of patients with degenerative diseases. Mortality from such neurodegenerative diseases as Parkinson's disease (PD), Alzheimer's, and cerebrovascular disease will increase, contrary to that of infectious diseases such as tetanus, meningitis, and Japanese encephalitis [2]. PD was first reported by James Parkinson in 1817 in London, but the concept of the disease continued to evolve the present level of understanding. PD is characterized by loss of dopaminergic (DA) neurons in the substantia nigra pars compacta $(\mathrm{SNpc})$ and the presence

Copyright: Adi, et al. Open Access. This article is distributed under the terms of the Creative Commons Attribution 4.0 International License (http://creativecommons.org/licenses/by/4.0/), which permits unrestricted use, distribution, and reproduction in any medium, provided you give appropriate credit to the original author(s) and the source, provide a link to the Creative Commons license, and indicate if changes were made. The Creative Commons Public Domain Dedication waiver (http://creativecommons.org/ publicdomain/zero/1.0/) applies to the data made available in this article, unless otherwise stated. of intraneuronal inclusions (Lewy bodies) [3]. It has multifactorial causes such as infection at a young age, environmental factors, neurotoxic substances (paraquat [PQ] dichloride, rotenone, maneb, MPTP, etc.), metabolic diseases, neurodegenerative diseases, and genetic factors [3-5]. To generate disease symptoms, the loss of nigral neurons must be at least $50 \%$, and at autopsy, most cases show a greater than $80 \%$ reduction [6]. The loss of nigral neurons will result in a deficiency of dopamine within the basal ganglia, leading to a movement disorder known as parkinsonian symptoms. These include bradykinesia, muscular rigidity, rest tremor, and postural, and gait impairment [7].

To date, available therapies for PD only treat symptoms of the disease. Several drugs that enhance intracerebral dopamine concentrations or stimulates dopamine receptors include levodopa (L-DOPA), dopamine agonists, and monoamine-oxidase inhibitors; these are effective at alleviating PD symptoms $[7,8]$. L-DOPA has proven to be the most reliable and efficacious for the restoration of dopamine in PD. Unlike dopamine, L-DOPA is transported through the bloodbrain barrier by the L-system large amino neutral amino acid transporter. Once it transported to the central nervous system, L-DOPA is converted into 
dopamine by aromatic-amino-acid decarboxylase [8]. Since it can be found in Mucuna pruriens (MP) seeds, studies aiming to evaluate the effect of MP supplementation in PD patients have been held in many countries. However, the pharmaceutical composition of MP seeds, the use of MP seed powder, and the method of extracting the substance from MP have been reported by Giessen et al. [9] in a United States Patent Application Publication. In Indonesia, particularly in the Yogyakarta region and surrounding areas, MP seed is known as koro benguk. It has been utilized as the main ingredients to made "tempe koro benguk," a product of fermented MP seeds. In addition, L-DOPA can still be extracted from this form.

The neuroprotective effects of MP extract in a PD animal model have been reported by many researchers [10-14]. However, the neuroprotective effect of n-propanol extract from tempe koro benguk and boiled koro benguk has not been studied. This research was carried out to reveal the neuroprotective effect of n-propanol extract of boiled and fermented koro benguk, as an alternative drug for PD prevention in the future.

\section{Materials and Methods \\ Ethical approval}

All the methods and treatments of animals were approved by the Ethical Clearance Committee of Integrated Research and Examination Laboratory (LPPT), Universitas Gadjah Mada, with the certificate number: 00018/04/LPPT/V/2016.

\section{Experimental animals}

25 male adult Wistar rats were used in this research. Male rats were selected to homogenize the experimental animals since female rats have hormonal cycles that can affect the experiment. These rats were divided into five groups. Group I $(n=5)$, as the healthy control group, received an injection of Aqua Pro Injection (DW-14-R5, Aqua pro Injection, PT. IKAPHARMINDO PUTRAMAS, Jakarta-Indonesia) $1 \mathrm{ml} / \mathrm{kg}$ BW intraperitoneally twice a week for 3 weeks. Group II $(n=5)$, as the PD-induced group, was injected with PQ dichloride at a dose of $7 \mathrm{mg} / \mathrm{kg} \mathrm{BW}$ intraperitoneally twice a week for 3 weeks. Injection of PQ dichloride intraperitoneally with appropriate dose and period will lead parkinsonism in rats. The other fifteen rats were divided into three groups, IIIA $(n=5)$, IIIB $(n=5)$, and IIIC $(n=5)$. These groups received PQ induction and extracted supplementation in the same week. The PQ induction protocol was the same as in Group II, and the extract administered to Group IIIA, IIIB, and IIIC, respectively, were fresh koro benguk n-propanol extract, boiled koro benguk n-propanol extract, and fermented koro benguk n-propanol extract. The dose of extract for all three groups was $70 \mathrm{mg} / \mathrm{kg} \mathrm{BW}$, given orally every day for 3 weeks. Koro benguk seeds were obtained from Kulon Progo, Special Administrative Region of Yogyakarta, Indonesia. Koro benguk plant was identified in Laboratory of Plant Systematics, Faculty of Biology, Universitas Gadjah Mada. The results confirmed that koro benguk we used was the seed of MP. The extractions were done in Integrated Research and Testing Laboratory (LPPT), Universitas Gadjah Mada.

\section{Sample collection and histological preparation}

On day $24^{\text {th }}$, all animals were perfused transcardially with physiological $\mathrm{NaCl}$ and fixed with phosphate-buffered paraformaldehyde $4 \%$. The brain was removed then fixed again in the same fixative solution. The SNpc region was determined with the aid of the rat brain atlas that was established by Paxinos and Watson [15]. The left half of the brain was embedded in paraffin then sliced to a thickness of $4 \mu$ to estimate the total number of DA neurons in SNpc based on the stereological method explained by Boyce et al. [16]. DA neurons were identified on the basis of immunohistochemical staining with the primary antibody rabbit anti-tyrosine hydroxylase (TH) $(1 / 500$, Boster Immunoleader, Cat No: PB9449). The immunoreactivities (IRs) were visualized with the Starr Trek Universal HRP Detection kit (Biocare Medical, Cat No: STUHRP700 H, L10).

\section{Statistical analysis}

Average total numbers of TH-IR neurons in $\mathrm{SNpc}$ in all five groups were analyzed by one-way ANOVA using SPSS ver.16 to test for significant differences between the groups.

\section{Results}

Immunovisualization using the Starr Trek Universal HRP Detection system resulted in the formation of a brown precipitate within the cell body and the axonal and dendritic processes. The TH-IR cells that were found in the SNpc, as marked by a brown precipitate within the cell, were identified as DA neurons. Distinct IRs of TH-IR cells were observed between the five groups. We observed a high intensity of TH-IR cells for most of the samples in Group II, in contrast to Group I. The other three groups, in order from the highest to the lowest intensity of IR, were Group IIIC, Group IIIB, and Group IIIA. With the stereology method, the total number of TH-IR cells in the SNpc can be counted without bias. The average total number of TH-IR cells in the SNpc of Group I, the healthy control group, was the highest of all five groups. Group II, as the PD-induced group, showed the lowest average total number of TH-IR cells in the SNpc. Of the three other groups, the highest average total number of TH-IR cells in the SNpc was in Group IIIB, followed by Group IIIC, and finally Group IIIA. The data are shown in Table-1.

Statistical analysis revealed significant differences in the average total number of TH-IR cells in the SNpc between the five groups. The total number of TH-IR cells in the SNpc Group II was significantly lower than that in Group I. On the other hand, the 
Table-1: Average total number of TH-IR cells in the SNpc of five groups.

\begin{tabular}{lccccc}
\hline TH-IR cells & \multicolumn{5}{c}{ 3-week treatment (mean $\mathbf{c}$ - $)$} \\
\cline { 2 - 6 } & Group I & Group II & Group IIIA & Group IIIB & Group IIIC \\
\hline Rat 1 & 22.950 & 11.424 & 13.668 & 21.828 & 16.218 \\
Rat 2 & 26.112 & 13.362 & 16.218 & 18.564 & 21.012 \\
Rat 3 & 31.416 & 12.546 & 14.994 & 16.626 & 19.482 \\
Rat 4 & 25.704 & 15.606 & 17.850 & 19.482 & 15.810 \\
Rat 5 & 29.274 & 10.812 & 14.688 & 19.788 & 18.870 \\
Mean \pm SD & $27.091 \pm 3.298$ & $12.750 \pm 1.877$ & $15.484 \pm 1.605$ & $19.258 \pm 1.894$ & $18.278 \pm 2.214$ \\
\hline
\end{tabular}

$\mathrm{SD}=$ Standard deviation, $\mathrm{TH}-\mathrm{IR}=$ Tyrosine hydroxylase immunoreactive, SNpc=Substantia nigra pars compacta

total number TH-IR cells in the SNpc in Group IIB and Group IIIC were greater than that in Group II, although they were still lower than that in Group I. Surprisingly, there was no significant difference between Group IIIA and Group II.

\section{Discussion}

Immunohistochemical staining using the primary antibody anti-TH to detect DA neurons has been reported by many researchers [17-19]. The TH-IR found in this study were similar to those reported by Nair-Roberts et al. [17], who used the immunolabeling peroxidase-DAB system, which resulted in brown precipitation in the cell body, axon, and dendrite process. Furthermore, Nair-Roberts et al. [17] explained that there was also a light brown color in the nucleus of the neuron, although its intensity was always lower than that seen in the cell cytoplasm with a clear visible nucleus. DA neurons could be detected by immunohistochemical staining with primary antibody against dopamine or an enzyme involved in its synthesis [20].

Differences in the intensity of TH-IR in immunohistochemical staining could be interpreted as differences in $\mathrm{TH}$ protein expression [21]. The higher intensity of TH-IR cells in the SNpc Group II indicated higher TH protein in DA neurons compared with Group I. The greater need for TH protein to convert tyrosine to L-DOPA before further conversion to dopamine is allegedly caused by the decreasing number of DA neurons in the SNpc of PD-induced rats. TH is "the rate-limiting enzyme" in the catecholamine system $[20,22]$. When the synapse in catecholamine neurons needs more neurotransmitter, this enzyme would be activated to convert more L-DOPA, since L-DOPA is the precursor for other catecholamine neurotransmitters $[22,23]$. A higher L-DOPA content in the fresh seed extract compared with the boiled and fermented seed extract [24] reduce the need for $\mathrm{TH}$ to convert more L-DOPA in PD-induced rats supplemented with the fresh seed extract. This hypothesis was supported by lower TH-IR in Group IIIA compared with Groups IIIB and IIIC. The TH-IR of Group IIIC was the highest because fermented seeds contained the least L-DOPA.

The data in Figure 1 showed a significant decrease in TH-IR cells in the SNpc of Group II compared with Group I. Induction of PQ at a dosage of $7 \mathrm{mg} / \mathrm{kg}$ BW twice a week for 3 weeks decreased the number of DA neurons by approximately $53 \%$. This result was similar to that reported by Somayajulu-Nitu et al. [18] that induction of PQ at a dosage of $10 \mathrm{mg} / \mathrm{kg} \mathrm{BW}$ once a week for 3 weeks could reduce DA neurons in the SNpc about $65 \%$. A different result was offered by Fahim et al. [25], who reported a loss of approximately $32 \%$ of DA neurons in the SNpc of rats induced with PQ at a dose of $10 \mathrm{mg} / \mathrm{kg}$ BW every day for 3 weeks. It seems that the mechanism of DA neuronal death caused by PQ was dose-dependent [26-28]. Toxicity of PQ against cells involves redox cycling and the production of reactive oxygen species (ROS), free radicals that lead to oxidative stress [29,30]. The ROS, especially $\mathrm{O}_{2}^{-}$and $\mathrm{H}_{2} \mathrm{O}_{2}$, can cause damage to biological substances, including nucleic acids and amino acids [31]. However, the most destructive effect of free radicals is the induction of lipid peroxidation [32]. The plasma membrane, composed of a phospholipid bilayer, is the primary target of ROS, which causes cell death.

This study revealed evidence that n-propanol extract of processed koro benguk seeds, both boiled and fermented, have a higher neuroprotective effect than fresh seeds. This was shown by the significantly higher average total number of TH-IR cells in Groups IIIB and IIIC compared with Group II, although it could not reach the same level as Group I. In contrast, Group IIIA was not significantly different from Group II as the PD-induced group. This evidence showed that the neuroprotective effect not simply caused by the presence of L-DOPA in koro benguk. The highest L-DOPA content could be found in fresh seed extract [24], but its neuroprotective effect was not as high as that of the extract from boiled and fermented seeds. Yadav et al. [14] explained in their report that the neuroprotective effect of koro benguk in a PD animal model comes from an alkaloid antioxidant or another antioxidant such as ursolic acid contained in MP seeds/ koro benguk. There are more than 50 substances contained in MP seeds [33]. Which one of the substances and the optimal processing method to use on seeds, that act as the best neuroprotective agents against PD in an animal model requires further exploration.

\section{Conclusion}

The average total number of TH-IR cells in SNpc of a PD rat model administered n-propanol extract of boiled and fermented seeds was statistically significantly higher than in the control PD rat model. There was no significant difference between the average 


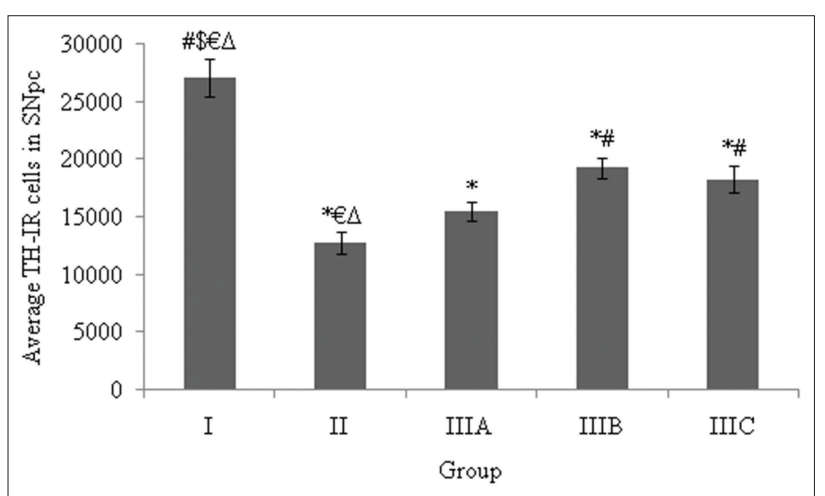

Figure-1: Diagram showing the average total number of TH-IR cells in the SNpc of the five groups. The symbol * indicates a significant difference compared with Group I; \# indicates a significant difference compared with Group II; \$ indicates a significant difference compared with Group IIIA; $€$ indicates a significant difference compared with Group IIIB; $\Delta$ indicates a significant difference compared with Group IIIC $(p<0.05)$.

total numbers of TH-IR cells in the SNpc of a PD rat model administered n-propanol extract of fresh seeds and the control PD rat model. n-Propanol extract of boiled and fermented seeds could provide a higher neuroprotective effect against DA neurons than fresh seeds in a PD rat model.

\section{Authors' Contributions}

TWP designed this study. YKA perform the experimental under the guidance of TWP. YKA and RW analyzed the result. YKA and TWP drafted and revised the manuscript. All the authors read and approved the final manuscript.

\section{Acknowledgments}

This study was conducted by the support of the Grant for Scientific Research (PUPT UGM 2016) from Directorate General of Higher Education, Ministry of Research, Technology and Higher Education, Republic Indonesia with grant number: 015/SP2H/LT/ DRPM/II/2016.

\section{Competing Interests} interests.

The authors declare that they have no competing

\section{References}

1. WHO. (1998) The World Health Report 1998-Life in the $21^{\text {st }}$ Century: A Vision for All. World Health Organization, Geneva.

2. WHO. (2006) Neurological Disorders: Public Health Challenges. World Health Organization, Geneva.

3. Mackenzie, I.R.A. (2005) Neuropathology of atypical parkinsonian disorders. In: Litvan, I. (Eds). Atypical Parkinsonian Disorders. Current Clinical Neurology. Humana Press, Philadelphia, PA.

4. Uversky, V.N. (2004) Neurotoxicant-induced animal models of Parkinson's disease: Understanding the role of rotenone, maneb, and paraquat in neurodegeneration. Cell Tissue Res., 318: $225-241$

5. Logroscino, G. (2005) The Role of early life environmental risk factors in Parkinson disease: What is the evidence?
Environ. Health Perspect., 113(9): 1234-1238.

6. Fearnley, J.M. and Lees, A.J. (1991) Ageing and Parkinson's disease: Substantia nigra regional selectivity. Brain., 114: 2283-2301.

7. Kalia, L.V. and Lang, A.E. (2015) Parkinson's disease. Lancet., 386: 896-912.

8. Stansley, B.J. and Yamamoto, B.K. (2015) L-dopa and brain serotonin system dysfunction. Toxics., 3(1): 75-88.

9. Giessen, R.V.D., Olanow, W., Lees, A. and Wagner, H. (2006) Pharmaceutical Compositions and Uses Comprising Mucuna pruriens Seed Powder and Extracts thereof in the Treatment of Neurological Disease. United States Patent, US $0165822 \mathrm{~A} 1$.

10. Manyam, B.V., Dhanasekaran, M. and Hare, T.A. (2004) Neuroprotective effects of the antiparkinson drug Mucuna pruriens. Phytother. Res., 18(9): 706-712.

11. Sabesan, M. and Subramanian, A. (2010) Neuroprotective effect of nanomucuna (Mucuna Pruriens Gold Nanoparticle) on MPTP induced parkinsonism in male mice. J Neurochem., 115: 56-66.

12. Madhyastha, S., Chauhan, R., Rao, G.M. and Hema, U. (2011) Neuroprotective effects of Mucuna pruriens against stress-induced oxidative damage. J. Physiol. Biomed. Sci., 24(2): 28-33.

13. Yadav, S.K., Prakash, J., Chouhan, S., Westfall, S., Verma, M., Singh, T.D. and Singh, S.P. (2014) Comparison of the neuroprotective potential of Mucuna pruriens seed extract with estrogen in 1-methyl-4phenyl-1,2,3,6-tetrahydropyridine (MPTP)-induced PD mice model. Neurochem. Int., 65: 1-13.

14. Yadav, S.K., Rai, S.N. and Singh, S.P. (2016) Mucuna pruriens shows neuroprotective effect by inhibiting apoptotic pathways of dopaminergic neurons in the paraquat mouse model of parkinsonism. Eur. J. Pharm. Med. Res., 3(8): 441-451.

15. Paxinos, G. and Watson, C. (2007) The Rat Brain: In Stereotaxic Coordinates. $6^{\text {th }}$ ed. Elsevier, China.

16. Boyce, R.W., Dorph-Petersen, A.K., Lyck, L. and Gundersen, H.J.G. (2010) Design-based stereology: Introduction to basic concepts and practical approaches for estimation of cell number. Toxicol. Pathol., 38(7): 1011-1025.

17. Nair-Roberts, R.G., Chatelain-Badie, S.D., Benson, E., White-Cooper, H., Bolam, J.P. and Ungless, M.A. (2008) Stereological estimates of dopaminergic, GABAergic and glutamatergic neurons in the ventral tegmental area, substantia nigra and retrorubral field in the rat. Neuroscience., 152(4): 1024-1031.

18. Somayajulu-Nitu, M., Sandhu, J.K., Cohen, J., Sikorska, M., Sridhar, T.S., Matei, A., Borowy-Borowski, H. and Pandey, S. (2009) Paraquat induces oxidative stress, neuronal loss in substantia nigra region and parkinsonism in adult rats: Neuroprotection and amelioration of symptoms by water-soluble formulation of coenzyme Q10. BMC Neurosci., 10: 88.

19. Pangestiningsih, T.W., Wendo, W.D., Selan, Y.N., Amalo, F.A., Ndaong, N.A. and Lenda, V. (2014) Histological features of catecholaminergic neuron in substantia nigra induced by paraquat dichloride (1,1-dimethyl-4,4 bipyridinium) in Wistar rat as a model of Parkinson disease. IJ Biotech., 19(1): 91-98.

20. Smeets, W.J.A.J. and Rainer, A. (1994) Phylogeny Development of Catecholamine System in the CNS of Vertebrate. Cambridge Univ Press, Cambridge.

21. Kato, K., Yamaguchi-Yamada, M. and Yamamoto, Y. (2010) Short-term hypoxia increases tyrosine hydroxylase immunoreactivity in rat carotid body. J. Histochem. Cytochem., 58(9): 839-846.

22. Daubner, S.C., Le, T. and Wang, S. (2011) Tyrosine hydroxylase and regulation of dopamine synthesis. Arch. Biochem. Biophys., 508(1): 1-12.

23. Nagatsu, T. and Nagatsu, I. (2016) Tyrosine hydroxylase 
(TH), its cofactor tetrahydrobiopterin (BH4), other catecholamine-related enzymes, and their human genes in relation to the drug and gene therapies of Parkinson's disease (PD): Historical overview and future prospects. J. Neural. Transm., 123(11): 1255-1278.

24. Pengestiningsih, T.W., Susmiati, T. and Wijayanto, H. (2017) L-3,4-dihydroxyphenylalanine content as a neuroprotective material on fresh, cooked and fermented of koro benguk (Mucuna pruriens) beans. J. Vet., 18(1): 116-120.

25. Fahim, M.A., Nemmar, A., Shehab, S., Dhanasekaran, S., Yasin, J., Shafiullah, M. and Hasan, M. (2016) Vitamin E mitigates the decremental effect of paraquat on substantia nigra neurons. FASEB J., 30(1): 742.1.

26. Brooks, A.I., Chadwick, C.A., Gelbard, H.A., Cory-Slechta, D.A. and Federoff, H.J. (1999) Paraquat elicited neurobehavioral syndrome caused by dopaminergic neuron loss. Brain Res., 823(1-2): 1-10.

27. McCormack, A.L., Thiruchelvam, M., Manning-Bog, A.B., Thiffault, C., Langston, J.W., CorySlechta, D.A. and Monte, D.A. (2002) Environmental risk factors and Parkinson's disease: Selective degeneration of nigral dopaminergic neurons caused by the herbicide paraquat. Neurobiol. Dis., 10(2): 119-127.
28. Blesa, J., Trigo-Damas, I., Quiroga-Varela, A. and LopezGonzalez del Rey, N. (2016) Animal models of Parkinson's disease. In: Dorszewska, J. and Kozubski, W., (Ed). Challenges in Parkinson's Disease. InTechOpen, UK, p. 195-216.

29. Ray, S., Sengupta, A. and Ray. A. (2007) Effects of paraquat on antioxidant system in rats. Indian J. Exp. Biol., 45(5): 432-438.

30. Berry, C., La V.C. and Nicotera, P. (2010) Paraquat and Parkinson's disease. Cell Death Differ., 17(7): 1115-1125.

31. Chance, B., Sies, H. and Boveris, A. (1979) Hydroperoxide metabolism in mammalian organs. Physiol. Rev., 59(3): 527-605.

32. Repetto, M., Semprine, J. and Boveris, A. (2012) Lipid peroxidation: Chemical mechanism, biological implications and analytical determination. In: Catala, A., (Ed.). Lipid Peroxidation. InTechOpen, UK, p. 3-30.

33. Lieu, C.A., Venkiteswaran, K., Gilmour, T.P., Rao, A.N., Petticoffer, A.C., Gilbert, E.V., Deogaonkar, M., Manyam, B.V. and Subramanian, T. (2012) The antiparkinsonian and antidyskinetic mechanisms of Mucuna pruriens in the MPTP-treated nonhuman primate. Evid. Based Complement Alternat. Med., 2012(840247): 1-10. 